\title{
KARAKTERISTIK FISIOLOGI EMPAT ANTAGONIS ISOLAT Trichoderma sp. SEBAGAI AGENSIA HAYATI
}

\author{
Fitria Dewi Sulistiyono \\ Universitas Pakuan - Bogor \\ e-mail: fitria.sulistiyono@unpak.ac.id
}

\section{ABSTRACT \\ Characteristics of Four Physiology Antagonists Isolate of Trichoderma spp. as Biological Agents}

\begin{abstract}
Trichoderma $\mathrm{sp}$ is soil saprophyte, one of many parasites that causing plants disease. The purpose of this study was to determine the temperature and $\mathrm{pH}$ growth of Trichoderma sp. This study was designed with the experimental method. The treatments were the temperature factor with five levels (temperature 15, 20, 25,

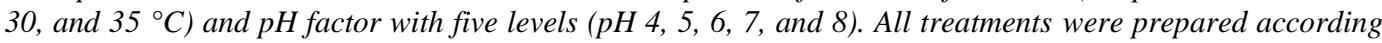
to completely randomized design factorial 5x5. Repetition was done 3 times. The results showed that Trichoderma sp. able to grow at pH 4, 5, 6, 7, and 8 and it also grow at temperatures of 15, 20, 25, 30 and $35^{\circ} \mathrm{C}$.
\end{abstract}

Keywords: Trichoderma sp, Four Physiology Antagonists, Biological Agents

\begin{abstract}
ABSTRAK
Trichoderma sp. adalah saprofit tanah, secara alami merupakan parasit yang menyerang banyak jenis penyebab penyakit tanaman. Tujuan dari penelitian ini adalah mengetahui suhu dan $\mathrm{pH}$ tumbuh Trichoderma sp. Penelitian ini dirancang dengan metode eksperimen. Perlakuan yang dicoba adalah faktor suhu dengan lima taraf (suhu 15, 20, 25, 30, dan $35^{\circ} \mathrm{C}$ ) dan faktor $\mathrm{pH}$ dengan lima taraf ( $\mathrm{pH} \mathrm{4,} \mathrm{5,} \mathrm{6,} \mathrm{7,} \mathrm{dan} \mathrm{8).} \mathrm{Semua}$ perlakuan disusun menurut Rancangan Acak Lengkap pola faktorial 5x5. Pengulangan dilakukan sebanyak 3 kali. Hasil penelitian menunjukan bahwa Trichoderma sp. mampu tumbuh pada $\mathrm{pH} 4,5$, 6, 7, dan 8 Trichoderma sp. Juga mampu tumbuh pada suhu $15,20,25,30$ dan $35^{\circ} \mathrm{C}$.
\end{abstract}

Kata kunci: Trichoderma sp, fisiologi empat antagonis, agensia hayati

\section{PENDAHULUAN}

Trichoderma sp. adalah saprofit tanah, secara alami merupakan parasit yang menyerang banyak jenis penyebab penyakit tanaman. Trichoderma sp. dapat menjadi hiper parasit pada beberapa jenis penyebab penyakit tanaman, pertumbuhannya sangat cepat dan tidak menjadi penyakit pada tanaman (Purwantisari dan Hastuti, 2009). Trichoderma sp. Mempunyai miselium halus tebal, pertumbuhan koloni radial dengan pola cincin yang jelas serta berwarna hijauputih (Octriana, 2011).

Trichoderma sp. mempunyai pertumbuhan yang lebih cepat dibandingkan dengan patogen yang menyerang tanaman. Pertumbuhannya bersifat agresif, mampu menutupi koloni fungi lain, dapat menghambat pertumbuhan patogen (Octriana, 2011). Ciri fisiologi dari isolat Trichoderma sp. antara lain adanya suhu dan $\mathrm{pH}$ yang spesifik untuk pertumbuhannya. Derajat keasaman $(\mathrm{pH})$ dan suhu yang spesifik akan menghasilkan pertumbuhan miselium yang maksimum, sehingga potensi sebagai agensia hayati dari Trichoderma sp. tersebut dapat dilakukan dengan optimum.

Menurut Hadar et al. (1984), pertumbuhan Trichoderma sp. akan lambat pada $\mathrm{pH} 2$ dan 8. Hajieghrari et al. (2008) melaporkan, T. harzianum T447 dapat tumbuh optimum pada $\mathrm{pH} 5$. Sobieralski et al. (2009) menyatakan bahwa fungi $T$. harzianum T447 dan $T$. 
harzianum T969 dapat tumbuh optimum pada suhu antara $25-30^{\circ} \mathrm{C}$. Pertumbuhan mengalami penurunan pada suhu kurang dari $25^{\circ} \mathrm{C}$ dan lebih dari $30^{\circ} \mathrm{C}$.

Pencirian fisiologi berhubungan dengan faktor lingkungan yang memengaruhi pertumbuhan suatu sumber agensia, antara lain suhu dan derajat keasaman $(\mathrm{pH})$. Suhu dan $\mathrm{pH}$ merupakan faktor yang berhubungan dengan manipulasi pertumbuhan, sporulasi dan kemampuan saprofit fungi pada perakaran. Pencirian biokimia berhubungan dengan senyawa metabolit yang dihasilkan oleh sumber agensia, termasuk di dalamnya antibiotika baik volatil dan non-volatil serta adanya enzim ekstrasel. Produksi metabolit ini akan dipengaruhi oleh suhu dan $\mathrm{pH}$ dari sumber agensia tersebut (Kredics et al., 2003 dan Howell, 2003).

Faktor utama yang sangat menentukan keberhasilan dalam pengembangan agensia hayati untuk pengendalian patogen tanaman adalah ketepatan dalam pemilihan jenis dan sumber agensia. Selanjutnya terhadap sumber agensia tersebut perlu dilakukan pencirian agar potensinya dapat tergali secara optimum. Pencirian dapat meliputi kajian fisiologi dan biokimia (Pelczar dan Chan, 1986).

\section{BAHAN DAN METODE}

\section{Bahan dan Alat}

Bahan yang digunakan dalam penelitian adalah 4 isolat Trichoderma sp., yaitu $T$. harzianum isolat pisang (Haryono et al., 2009), Trichoderma sp. isolat nenas (koleksi Loekas Soesanto), $T$. harzianum isolat bawang merah (Santoso et al., 2007) dan T. harzianum isolat jahe (Soesanto et al., 2005). Isolat patogen yang digunakan adalah $F$. oxysporum (koleksi Loekas Soesanto), alkohol, spirtus, medium PDA dengan $\mathrm{pH} 4,5,6,7,8$.

Alat yang digunakan adalah cawan Petri dengan berdiameter $9 \mathrm{~cm}$ (Iwaki Pyrex $^{\circledR}$ ), beaker glass $1000 \mathrm{ml}$ (Iwaki
Pyrex ${ }^{\circledR}$ ), labu Erlenmeyer $250 \mathrm{~mL}$ (Iwaki Pyrex $^{\circledR}$ ), gelas ukur $250 \mathrm{ml}$ (Iwaki Pyrex ${ }^{\circledR}$ ), autoclave, oven dengan (Memmert), laminar airflow, timbangan analitik (Explorer Ohous), kompor gas, thermometer, lemari es (Samsung), $\mathrm{pH}$ meter.

Penelitian ini dirancang dengan metode eksperimen. Perlakuan yang dicoba adalah faktor suhu dengan lima taraf (suhu 15, 20, 25, 30, dan $35^{\circ} \mathrm{C}$ ) dan faktor $\mathrm{pH}$ dengan lima taraf $(\mathrm{pH} 4,5,6$, 7, dan 8). Semua perlakuan disusun menurut Rancangan Acak Lengkap pola faktorial $5 \times 5$. Pengulangan dilakukan sebanyak 3 kali.

\section{METODE}

Penentuan ciri Trichoderma sp. terhadap pengaruh $\mathrm{pH}$ dan suhu dilakukan dengan menghitung diameter koloni. Masing-masing isolat $(\phi 10 \mathrm{~mm})$ diinokulasikan ke dalam medium PDA (Potatoes Dextrose Agar) dengan kisaran pH 4, 5, 6, 7, 8 dengan penambahan 0,1 N HCL atau $\mathrm{NaOH}$ sebelum disterilkan untuk menentukan $\mathrm{pH}$ di atas. Seluruh isolat diinkubasi pada suhu yang berbeda yaitu $15 \pm 1,20 \pm 1,25 \pm 1, \quad 30 \pm 1$ dan $35 \pm 1^{\circ} \mathrm{C}$ selama 7 hari dengan menggunakan inkubator (Hajieghrari et al., 2008). Data yang diperoleh dari pencirian fisiologi dianalisis dengan Anova dua arah, dengan menggunakan software Minitab 14.

\section{Waktu dan Tempat}

Penelitian telah dilakukan di Laboratorium Mikologi, Fakultas Biologi Universitas Jenderal Soedirman, Purwokerto. Penelitian dilakukan dalam waktu 3 bulan dari bulan Mei 2013-Juli 2013.

\section{HASIL PENELITIAN}

Hasil pengamatan dan diameter pertumbuhan berdasarkan suhu masingmasing isolat, Trichoderma sp. dapat 
tumbuh pada suhu $15^{\circ} \mathrm{C}, 20^{\circ} \mathrm{C}, 25^{\circ} \mathrm{C}$, $30^{\circ} \mathrm{C}$, dan $35^{\circ} \mathrm{C}$ (Tabel 1). Berdasarkan perbedaan pada penelitian ini, Trichoderma sp. dapat beradaptasi dengan berbagai suhu. Suhu pertumbuhan yang telah diatur dari $15^{\circ} \mathrm{C}$ hingga $35^{\circ} \mathrm{C}$, menunjukkan bahwa Trichoderma sp. baik isolat pisang, bawang merah, nenas maupun jahe masih dapat tumbuh pada kisaran suhu tersebut. Hasil ini sesuai dengan penelitian AlMahareeq et al. (2005) bahwa Trichoderma sp. di Palestina mampu tumbuh pada suhu $10-35^{\circ} \mathrm{C}$ dan tidak mampu tumbuh di atas suhu $40^{\circ} \mathrm{C}$. Soesanto (2008), menyatakan bahwa suhu optimum untuk pertumbuhan Trichoderma sp. berkisar $15-35^{\circ} \mathrm{C}$.

Hasil penelitian bahwa Trichoderma sp. mampu tumbuh pada suhu $15^{\circ} \mathrm{C}$ dengan diameter Pertumbuhan sebesar 9 $\mathrm{cm}$ pada hari ke-7. Koloni isolat berwarna putih karena pada suhu $15^{\circ} \mathrm{C}$, Trichoderma tidak mampu membentuk konidium hingga hari ke-7. Berbeda dengan suhu $15^{\circ} \mathrm{C}$, pada suhu $20^{\circ} \mathrm{C}$, $25^{\circ} \mathrm{C}$, dan $30^{\circ} \mathrm{C}$ menunjukkan bahwa Trichoderma sp. mampu membentuk konidium pada seluruh bagian cawan petri (berdiameter $9 \mathrm{~cm}$ ) dengan pola lingkaran pada hari ke-7, sehingga warna koloni yang terbentuk adalah hijau muda. Pada suhu $35^{\circ} \mathrm{C}$, hari ke-7 pertumbuhan Trichoderma sp. mengalamai penurunan dibandingkan pada suhu $15-30^{\circ} \mathrm{C}$, yaitu
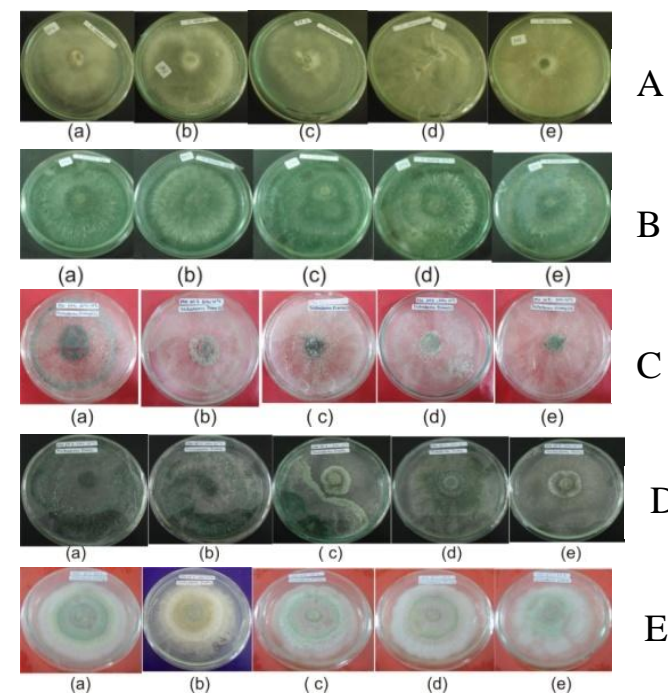

Gambar 1. Trichoderma sp. pada berbagai suhu dan $\mathrm{pH}$ dengan kisaran diameter antara 7,5-8,4 $\mathrm{cm}$. Warna hijau muda terlihat hanya di daerah tengan cawan petri, hal ini dikarenakan konidium yang terbentuk hanya berada di daerah tersebut.

Koloni Trichoderma sp. tumbuh dengan cepat dan matang sejak hari ke-5 (diameter pertumbuhan sebesar $9 \mathrm{~cm}$ ) dalam medium dextrose agar suhu $25^{\circ} \mathrm{C}$, sedangkan dalam medium oat agar Trichoderma sp. optimum pada suhu $20^{\circ}$ C (Soesanto, 2008; Gupta dan Sharma, 2013). Pertumbuhan Trichoderma sp. dimulai setelah 5-6 jam pada medium kultur agar. Koloni Trichoderma sp. berwarna putih, dengan konidium akan menyebar dan menebal membentuk pola cincin berwana kehijauan. Koloni menjadi berwarna karena adanya pembentukan konidium dan perkembangan konidium akan berakhir setelah 3-5 hari (Gams dan Meyer, 1998; Howell, 2003; Soesanto, 2008; dan Octriana, 2011).

Perbedaan diameter pertumbuhan dan warna koloni yang terbentuk dari suhu $15-35^{\circ} \mathrm{C}$ disebabkan faktor fisik yang berbeda, dalam hal ini adalah perbedaan suhu yang digunakan. Menurut Monte (2001) perubahan struktur, bentuk, ukuran, warna miselum suatu fungi tergantung pada kondisi fisik lingkungannya, salah satunya adalah suhu.

\section{Keterangan:}
A. Trichoderma sp. pada suhu $15^{\circ} \mathrm{C}$
B. Trichoderma sp. pada suhu $20^{\circ} \mathrm{C}$
C. Trichoderma sp. pada suhu $25^{\circ} \mathrm{C}$
D. Trichoderma sp. pada suhu $30^{\circ} \mathrm{C}$
E. Trichoderma sp. pada suhu $35^{\circ} \mathrm{C}$

$\begin{array}{ll}\text { (a) } & \mathrm{pH} 4 \\ \text { (b) } & \mathrm{pH} 5 \\ \text { (c) } & \mathrm{pH} 6 \\ \text { (d) } & \mathrm{pH} 7 \\ \text { (e) } & \mathrm{pH} 8\end{array}$


Tabel 1. Diameter pertumbuhan Trichoderma sp. dalam berbagai suhu dan $\mathrm{pH}$

\begin{tabular}{|c|c|c|c|c|c|}
\hline \multirow[b]{2}{*}{ No } & \multirow[b]{2}{*}{ Suhu/pH } & \multicolumn{4}{|c|}{ Diameter pertumbuhan $(\mathrm{cm})$} \\
\hline & & $\begin{array}{c}\text { Trichoderma } \\
\text { sp. Isolat } \\
\text { pisang+stdv }\end{array}$ & $\begin{array}{c}\text { Trichoderma sp. } \\
\text { Isolat } \\
\text { bawang+stdv }\end{array}$ & $\begin{array}{c}\text { Trichoderma sp. } \\
\text { Isolat } \\
\text { nenas } \pm \text { stdv }\end{array}$ & $\begin{array}{c}\text { Trichoderma } \\
\text { sp. Isolat } \\
\text { jahe } \pm \text { stdv }\end{array}$ \\
\hline 1 & $15 \mathrm{a}$ & $9,0 \pm 0,0$ & $9,0 \pm 0,0$ & $9,0 \pm 0,0$ & $9,0 \pm 0,0$ \\
\hline 2 & $15 b$ & $9,0 \pm 0,0$ & $9,0 \pm 0,0$ & $9,0 \pm 0,0$ & $9,0 \pm 0,0$ \\
\hline 3 & $15 \mathrm{c}$ & $9,0 \pm 0,0$ & $9,0 \pm 0,0$ & $9,0 \pm 0,0$ & $9,0 \pm 0,0$ \\
\hline 4 & $15 d$ & $9,0 \pm 0,0$ & $9,0 \pm 0,0$ & $9,0 \pm 0,0$ & $9,0 \pm 0,0$ \\
\hline 5 & $15 \mathrm{e}$ & $9,0 \pm 0,0$ & $9,0 \pm 0,0$ & $9,0 \pm 0,0$ & $9,0 \pm 0,0$ \\
\hline 6 & $20 \mathrm{a}$ & $9,0 \pm 0,0$ & $9,0 \pm 0,0$ & $9,0 \pm 0,0$ & $9,0 \pm 0,0$ \\
\hline 7 & $20 \mathrm{~b}$ & $9,0 \pm 0,0$ & $9,0 \pm 0,0$ & $9,0 \pm 0,0$ & $9,0 \pm 0,0$ \\
\hline 8 & $20 \mathrm{c}$ & $9,0 \pm 0,0$ & $9,0 \pm 0,0$ & $9,0 \pm 0,0$ & $9,0 \pm 0,0$ \\
\hline 9 & $20 \mathrm{~d}$ & $9,0 \pm 0,0$ & $9,0 \pm 0,0$ & $9,0 \pm 0,0$ & $9,0 \pm 0,0$ \\
\hline 10 & $20 \mathrm{e}$ & $9,0 \pm 0,0$ & $9,0 \pm 0,0$ & $9,0 \pm 0,0$ & $9,0 \pm 0,0$ \\
\hline 11 & $25 \mathrm{a} \backslash$ & $9,0 \pm 0,0$ & $9,0 \pm 0,0$ & $9,0 \pm 0,0$ & $9,0 \pm 0,0$ \\
\hline 12 & $25 b$ & $9,0 \pm 0,0$ & $9,0 \pm 0,0$ & $9,0 \pm 0,0$ & $9,0 \pm 0,0$ \\
\hline 13 & $25 \mathrm{c}$ & $9,0 \pm 0,0$ & $9,0 \pm 0,0$ & $9,0 \pm 0,0$ & $9,0 \pm 0,0$ \\
\hline 14 & $25 \mathrm{~d}$ & $9,0 \pm 0,0$ & $9,0 \pm 0,0$ & $9,0 \pm 0,0$ & $9,0 \pm 0,0$ \\
\hline 15 & $25 \mathrm{e}$ & $9,0 \pm 0,0$ & $9,0 \pm 0,0$ & $9,0 \pm 0,0$ & $9,0 \pm 0,0$ \\
\hline 16 & $30 a$ & $9,0 \pm 0,0$ & $9,0 \pm 0,0$ & $9,0 \pm 0,0$ & $9,0 \pm 0,0$ \\
\hline 17 & $30 \mathrm{~b}$ & $9,0 \pm 0,0$ & $9,0 \pm 0,0$ & $9,0 \pm 0,0$ & $9,0 \pm 0,0$ \\
\hline 18 & $30 \mathrm{c}$ & $9,0 \pm 0,0$ & $9,0 \pm 0,0$ & $9,0 \pm 0,0$ & $9,0 \pm 0,0$ \\
\hline 19 & $30 \mathrm{~d}$ & $9,0 \pm 0,0$ & $9,0 \pm 0,0$ & $9,0 \pm 0,0$ & $9,0 \pm 0,0$ \\
\hline 20 & $30 \mathrm{e}$ & $9,0 \pm 0,0$ & $9,0 \pm 0,0$ & $9,0 \pm 0,0$ & $9,0 \pm 0,0$ \\
\hline 21 & $35 a$ & $8,17 \pm 0,46$ & $7,97 \pm 0,41$ & $8,23 \pm 0,18$ & $7,97 \pm 0,41$ \\
\hline 22 & $35 b$ & $8,17 \pm 0,15$ & $7,57 \pm 0,41$ & $8,43 \pm 0,35$ & $7,57 \pm 0,41$ \\
\hline 23 & $35 \mathrm{c}$ & $8,47 \pm 0,25$ & $8,00 \pm 0,00$ & $7,80 \pm 0,79$ & $8,00 \pm 0,00$ \\
\hline 24 & $35 \mathrm{~d}$ & $8,47 \pm 0,25$ & $8,27 \pm 0,25$ & $8,63 \pm 0,15$ & $8,27 \pm 0,25$ \\
\hline 25 & $35 \mathrm{e}$ & $8,63 \pm 0,06$ & $8,53 \pm 0,48$ & $8,23 \pm 0,15$ & $8,53 \pm 0,47$ \\
\hline
\end{tabular}

Menurut Miles dan Chang (1997) pengaturan suhu optimum pada pertumbuhan fungi berhubungan dengan pembentukan struktur khusus untuk pertahanan hidup. Contohnya adalah pembentukan konidium pada Trichoderma sp. yang merupakan struktur khusus untuk reproduksi. Selain itu, suhu akan menentukan distribusi spesies fungi di alam. Suhu juga akan memengaruhi senyawa metabolit yang dihasilkan di antaranya dalah enzim. Enzim tersebut dapat dihasilkan pada saat fase eksponensial pertumbuhan fungi.

Seluruh isolat yang ditumbuhan pada kisaran $\mathrm{pH}$ berbeda menunjukkan bahwa isolat Trichoderma sp. selama 7 hari dapat tumbuh pada medium dengan $\mathrm{pH} \mathrm{4,} \mathrm{5,} \mathrm{6,} \mathrm{7,} \mathrm{dan} \mathrm{8.} \mathrm{Hal} \mathrm{ini} \mathrm{sesuai} \mathrm{dengan}$ pernyataan Kredics (2003) dan Soesanto (2008), bahwa kisaran pH pertumbuhan Trichoderma sp., yaitu 2-6. Hasil pengamatan menunjukkan bahwa pembentukan konidium lebih banyak 
terdapat pada medium dengan $\mathrm{pH}$ 4. Hal ini ditunjukkan dengan perubahan warna hijau yang paling dominan pada $\mathrm{pH} 4$ dibandingkan dengan $\mathrm{pH}$ lainnya. Kredics (2003) menyatakan bahwa $\mathrm{pH}$ optimum untuk pertumbuhan Trichoderma sp. adalah 4. Chet et al. (1981) menyatakan bahwa keasaman tingkat $\mathrm{pH}$ in vitro pada pertumbuhan Trichoderma sp. akan merangsang pembentukan konidium dan perkecambahan konidium.

Keberadaan $\mathrm{pH}$ berhubungan dengan aktivitas enzim yang dihasilkan selama pertumbuhan fungi. Pemisahan molekul menjadi ion yang terjadi di dalam permiabel membran sel fungi dipengaruhi oleh $\mathrm{pH}$. Molekul asam organik yang dibutuhkan oleh fungi dapat masuk ke dalam membran sel dengan $\mathrm{pH}$ rendah (asam), sehingga $\mathrm{pH}$ pertumbuhan yang dibutuhkan untuk pertumbuhan fungi adalah bersifat asam (Miles dan Chang, 1997).

Selain lingkungan abiotik, yang mendukung pertumbuhan Trichoderma sp. adalah kandungan nutrisi. Seluruh isolat Trichoderma sp. pada penelitian ini ditumbuhkan pada medium PDA yang menggunakan sumber karbon berupa Dglukosa, yang dimanfaatkan Trichoderma sp. untuk pertumbuhannya. Hal ini sesuai dengan pernyataan Mehta et al. (2012), yang menyatakan bahwa pertumbuhan Trichoderma sp. dipengaruhi oleh sumber karbon. Karbon dapat diperoleh dari monosakarida maupun disakarida. Selain itu, Soesanto (2008) menyatakan bahwa gula (glukosa) dimanfaatkan oleh T. harzianum sebagai sumber karbon, yang memiliki peran sebagai prekursor metabolit sekunder untuk menghambat perkecambahan konidium fungi patogen. Miles dan Chang (1997) menyatakan bahwa karbon digunakan sebagai sumber energi untuk melakukan aktivitas metabolisme di dalam sel fungi dan sebagai kerangka dalam pembentukan senyawa organik (karbohidrat, asam amino).

\section{KESIMPULAN}

1. Trichoderma sp. mampu tumbuh pada suhu $15,20,25,30$ dan $35^{\circ} \mathrm{C}$

2. Trichoderma sp. mampu tumbuh pada $\mathrm{pH} 4,5,6,7$, dan 8

\section{DAFTAR PUSTAKA}

Gams, W, and W. Meyer. 1998. What exactly is Trichoderma harzianum Rifai. Mycologia. 90: 904-915.

Gupta, V, and A.K. Sharma. 2013. Assesment of optimum temperature of Trichoderma harzianum by monitoring radial growth and population dynamics in different compost manures under different temperaturer. Octa Journal of Biosciences. 1(2): 151-157.

Hadar, Y., G.E. Harman, and A.G. Taylor. 1984. Evaluation of Trichoderma koningii and $T$. harzianum from New York soils for biological control of seed rot caused by Pythium spp. Phytopathology. 74(1): 106-110.

Hajieghrari, B., M.T. Giglou, M.R. Mohammadi, and A. Davari. 2008. Biological potential of some Iranian Trichoderma isolates in the control of soil borne plant pathogenic fungi. African journal of Biotechnology. 7(8): 967-972.

Kredics, L., Z. Antal, L. Manczinger, A. Szekeres, F. Kevei, and E. Nagy. 2003. Influence of environmental parameters on Trichoderma strains with 
biocontrol potential. Food

Technology and

Biotechnology. 41 (1): 37-42.

Monte, E. 2001. Editorial paper: understanding Trichoderma: Between agricultural biotechnology and microbial ecology. International Microbiology. 4: 1- 4 .

Octriana, L. 2011. Potensi agen hayati dalam menghambat pertumbuhan Phytium sp. secara in vitro. Buletin Plasma Nutfah. 17 (2):138-142.

Purwantisari, S, dan R.B. Hastuti. 2009. Uji antagonisme patogen Phytophthora Infestans penyebab penyakit busuk daun dan umbi Tanaman kentang dengan menggunakan Trichoderma spp. isolat lokal. Bioma. 11 (1): 24-32.

Sobieralski, K., M. Siwulski, and D. Frużyńska-Jóźwiak. 2009. Growth of aggressive isolates of Trichoderma aggressivum f. europaeum in dependence on temperature and medium. Phytopathologia. 53: 11-18. 